Short communication

\title{
IDENTIFICATION OF NOVEL SINGLE NUCLEOTIDE POLYMORPHISMS IN THE PRKAG3 GENE OF PAKISTANI RIVER BUFFALO
}

\author{
W. A. KHAN ${ }^{1,3}$, T. HUSSAIN ${ }^{2}$, M. E. BABAR ${ }^{2}$, A. NADEEM ${ }^{1}$, \\ A. R. $\operatorname{AWAN}^{1} \&$ F. M. M. T. MARIKAR ${ }^{4}$ \\ ${ }^{1}$ Institute of Biochemistry and Biotechnology, Faculty of Bio Sciences, University of \\ Veterinary and Animal Sciences, Lahore, Pakistan; ${ }^{2}$ Department of Molecular Biolo- \\ gy, Faculty of Science and Technology, Virtual University of Pakistan, Lahore, Paki- \\ stan, ${ }^{3}$ Department of Biotechnology, Faculty of Sciences, University of Sargodha, \\ Sargodha, Pakistan. ${ }^{4}$ General Sir John Kotelawala Defence University, Ratmalana, \\ Sri Lanka
}

\section{Summary}

Khan, W. A., T. Hussain, M. E. Babar, A. Nadeem, A. R. Awan \& F. M. M. T. Marikar 2019. Identification of novel single nucleotide polymorphisms in the PRKAG3 gene of Pakistani river buffalo. Bulg. J. Vet. Med., 22, No 3, 353-358.

Pakistani river buffalo is classified in five breeds out of which Kundi buffalo has been least documented. This study is designed to find single nucleotide polymorphisms (SNPs) in exonic and intronic regions of PRKAG3 (AMP-activated, Gamma3 non-catalytic subunit) gene in the Kundi buffalo. The PRKAG3 gene of 95 animals each from Kundi and Nili-Ravi were sequenced for identification of novel SNPs. Comparing with the Nili Ravi breed of buffalo PRKAG3 gene, six SNP sites were identified in the Kundi buffalo. The novel SNPs found in this work can function as a genomic indicator for genetic-phenotypic relationship of $P R K A G 3$ gene with milk and meat production in buffalo. This is the first report of SNPs in PRKAG3 gene of Kundi Buffalo.

Key words: AMPK, Pakistan, $P R K A G 3$, river buffalo, single nucleotide polymorphism

Water buffaloes are of prime importance in the lives of farmers and thus in the economies of many countries worldwide. They are not only draught animals, but also a source of meat, horns, skin, and particularly milk, which may be processed into cream, butter, yoghurt, and many kinds of cheese (Michelizzi et al., 2010).
The number of water buffaloes in the world has increased rapidly over the past few decades and according to FAO statistics (FAO, 2011) there are about 195 million buffaloes in the world. The current world scenario has glimpsed an amplified loss in wildlife diversity due to ever increasing human intrusion into ecological 
habitats. Although the trends of loss in livestock diversity are comparatively different, many breeds are near to losing their genetic identity due to the forced gene flow of superior traits from economically healthier populations. The commercially underestimated livestock breeds could provide great economic stimulus in the future in terms of the beneficial allele spectra they have gained because of adaptation to their environments. Therefore, the FAO Domestic Animal Diversity Information System (DAD-IS) and Domestic Animal Genetic Resources Information System (DAGRIS) have begun a worldwide campaign for the conservation of within- and between-breed genetic diversity in livestock for their sustainable future use befitting their economic and social value. The within- and between-breed genetic variability in livestock predicted by phenotypic attributes can nowadays be validated using molecular markers and their analysis with sophisticated statistical techniques (Toro et al., 2009).

Pakistani river buffalo has been grouped in five distinct breeds out of which Kundi is the least genetically documented. Home tract of Kundi lies on both sides of river Indus (Shah, 1994). The Pakistani buffalo breeds are conventionally reared and bred and there is an imperative need to study and improve the indigenous buffalo breeds for maximum production-efficiency. The sustainable growth in meat production in livestock needs not only managing resources but also reliance on the development of animal genetics. Adenosine monophosphateactivated protein kinase (AMPK) is one of most significant cellular enzyme involved in energy metabolism in the body of maximum of the mammals including buffaloes (Babar et al.., 2008). AMPK influences the meat quality traits comprising meat colour, tenderness, drip loss and cooking loss (Milan et al., 2000; Ciobanu et al., 2001). AMPK complex consists of seven subunits, amongst which two subunits $(\alpha 1$ and $\alpha 2$ ) are a member of catalytic alpha subunit, two ( $\beta 1$ and $\beta 2$ ) of regulatory beta subunit and three $(\gamma 1, \gamma 2$ and $\gamma 3)$ of regulatory gamma subunit (Carling, 2004; Crute et al., 1998). Protein kinase AMPactivated non-catalytic subunit gamma 3 (PRKAG3) gene encodes $\gamma 3$-peptide which is one of the three $\gamma$-isoforms $(\gamma 1, \gamma$ 2 and $\gamma 3$ ) of the $\gamma$-regulatory subunit of AMPK and with muscle-specific expression (Cheung et al., 2000). The relationship between PRKAG3 gene polymorphism and milk \& meat quality traits have already been described in bovine and porcine (Kowalewska-Luczak \& Kulig, 2011; Ryan et al., 2012). Due to the geographical seclusion Pakistani buffalo breed; Kundi can be a smart model for identification of novel single nucleotide polymorphisms (SNPs) in PRKGA3 gene and its association with meat and milk production and meat production traits. In the current study, we described through DNA sequencing, the locus specific novel polymorphisms in PRKAG3 gene of riverine buffalo; Kundi. Furthermore, it will provide information on the genetic relatedness of the Kundi with reference to the Nili Ravi, which can be employed to support the natural populations in the coming years if necessary and infer strategies for the enrichment of the GenBank samples for buffalo in Pakistan.

Samples collection. Ninety-five unrelated $(n=95)$ individuals of Kundi and Nili-Ravi breeds with typical phenotypic features were collected from the wild as well as from captive locations after rather extensive field search in their natural habitats. Ten $\mathrm{mL}$ blood was collected asepti- 
cally from each animal from the jugular vein of Kundi breeds which was approved by the Institutional Board of Study of Institute of Biochemistry and Biotechnology, University of Veterinary and Animal Sciences, Lahore with $0.5 \mathrm{M}$ ethylenediamine tetra-acetic acid (EDTA) as an anticoagulant. The blood samples were stored on ice immediately after collection. They were then brought to the laboratory and further stored temporarily at $-20{ }^{\circ} \mathrm{C}$ prior to DNA extraction. Additionally, 95 blood samples of Nili-Ravi breed; another well characterised Pakistani buffalo were obtained for reference study.

DNA extraction and quantification. The stored samples were thawed (at room temperature using water bath) for the genomic DNA isolation using DNA extraction kit (BioBasic, Canada) as per manufacturer's guidelines and stored at $-20{ }^{\circ} \mathrm{C}$ for further use. Quantification of the extracted DNA samples was carried out with the help of agarose gel electrophoresis $(0.8 \%)$ as well as NanoDrop (Thermo scientific, USA). Standard DNA/DNA ladder was added. All samples were brought to same level of concentration of $50 \mathrm{ng} / \mu \mathrm{L}$.

Primers and PCR amplification. Amplification used PRKAG3 specific primers given in Table 1 and available at GenBank, National Centre for Biotechnology Information (NCBI) using Primer 3 software and Insilico PCR web facility (Rozan \& Skaletsky, 2000). PCR was performed according to the protocol of primers set. DNA polymerase, polymerase chain reaction (PCR) buffer, dNTPs, $\mathrm{MgCl}_{2}$, genomic DNA and nuclease-free water were used for the amplification using thermocycler (IcyclerBioRad, USA). PCR was performed in reaction volume of $25 \mu \mathrm{L}$ using cycling conditions: initial denaturation at $95{ }^{\circ} \mathrm{C}$ for $4 \mathrm{~min}$ followed by 35 cycles of $94{ }^{\circ} \mathrm{C}$ for $1 \mathrm{~min} ; 54{ }^{\circ} \mathrm{C}$ for $1 \mathrm{~min} ; 72{ }^{\circ} \mathrm{C}$ for $1 \mathrm{~min}$ with final extension at $72{ }^{\circ} \mathrm{C}$ for $7 \mathrm{~min}$.

Sequencing. PCR amplifications were seen by running $6 \mu \mathrm{L}$ of PCR product mixed with $2 \mu \mathrm{L}$ of loading dye on $1.5 \%$ agarose gel at a constant voltage of $100 \mathrm{~V}$ for $50 \mathrm{~min}$ in $1 \times$ TAE buffer. The resulting bands were visualised under UV light using gel documentation system (BioRad, USA). The amplified PCR products were purified using DP203-TIANquick Mini Purification Kit (China) as per provided instructions. The quality of DNA was examined on $2 \%$ agarose gel. Purified PCR products were then sent to Singapore for Sanger's sequencing.

Table 1. List of primers used to amplify different regions of the PRKAG3 gene

\begin{tabular}{llll}
\hline Primer name & Primer sequence $\left(5^{\prime}-3^{\prime}\right)$ & $\begin{array}{l}\text { Product } \\
\text { size }\end{array}$ & $\begin{array}{l}\text { Primer } \\
\text { location }\end{array}$ \\
\hline PRKAG3F1 & GAGCAAGGAGACAGCACTTCA & 891 & Ex3, Int3, Ex4 \\
PRKAG3R1 & ACCTGTAGCATGGTGTCGAAGA & & \\
PRKAG3.UPSEQ1 & GACCTCAGCATCCAGGCT & & \\
PRKAG3.UPSEQ2 & GACAGTAACTCCATCTTCCA & \multirow{2}{*}{ Ex13 } & Ex10, Int10, \\
PRKAG3F2 & CCAAGCAGCGCACCCTGCT & & \\
PRKAG3R2 & CTTACAATCACATCAAAGCGG & & \\
PRKAG3.DNSEQ1 & ATGGTAGAGAACACTGTGTA & & \\
PRKAG3.DNSEQ2 & TTCCACAGATCTGCCTGCT & & \\
PRKAG3.DNSEQ3 & ATATAGCCTGAATCTGCGTG & & \\
PRKAG3.DNSEQ4 & GAGGTGAAATGACATGATTC & & \\
\hline
\end{tabular}


Identification of novel single nucleotide polymorphisms in the PRKAG3 gene of Pakistani river buffalo

lic representation of inter-breed polymor-

Table 2. Genotypes and allelic frequencies of the PRKAG3 gene

\begin{tabular}{lllllll}
\hline \multicolumn{2}{c}{ Genotypes } & & \multicolumn{3}{c}{ Allele Frequencies } \\
\hline & Name & Allele & Position & $\begin{array}{c}\text { Nili-Ravi } \\
(\mathrm{n}=95)\end{array}$ & $\begin{array}{c}\text { Kundi } \\
(\mathrm{n}=95)\end{array}$ & $\begin{array}{c}\text { Both breeds } \\
(\mathrm{n}=200)\end{array}$ \\
\hline Ex3 & NK1A & GG & 967 & 0.67 & 1.0 & 0.835 \\
& NK1B & AA & & 0.33 & 0 & 0.165 \\
& NK2A & GG & \multirow{2}{*}{1030} & 1.0 & 0.55 & 0.775 \\
& NK28 & GC & & 0 & 0.45 & 0.225 \\
\hline Int3 & NK3A & CC & 1070 & 0.53 & 1.0 & 0.765 \\
& NK3B & CT & & 0.37 & 0 & 0.185 \\
& NK3C & TT & & 0.10 & 0 & 0.05 \\
& NK4A & CC & \multirow{2}{*}{1382} & 0.47 & 1.0 & 0.735 \\
& NK4B & CT & & 0.38 & 0 & 0.19 \\
& NK4C & TT & & 0.15 & 0 & 0.075 \\
\hline Ex4 & NK5A & GG & 1489 & 0.46 & 0.32 & 0.39 \\
& NK5B & GA & & 0.35 & 0 & 0.175 \\
& NK5C & AA & & 0.19 & 0.68 & 0.435 \\
& & & & 0.58 & 0.67 & 0.625 \\
& & & 0.42 & 0.33 & 0.375 \\
\hline Int10 & NK6A & TT & 4875 & 0.67 & 1.0 & 0.835 \\
& NK6B & AA & & 0.33 & 0 & 0.165 \\
\hline
\end{tabular}

Bioinformatics analysis. The sequences were aligned by using NCBI BLAST tool. CodoncCode Aligner software was used for sequence editing, alignment and detection of variable sites. Multiple sequence alignments were executed with Clustal W.

In this study six SNPs were detected in the PRKAG3 gene of Pakistani Buffalo; Kundi and Nili-Ravi (Table 2). Two SNPs at position 1070 and 1489 were also included from this study in PRKAG3 gene of Nili-Ravi buffalo. The polymorphisms were observed at exon 3 , intron 3 , exon 4 and intron 10 of PRKAG3 gene of the Kundi buffalo. The variants NK1A and NK1B were found in Pakistani buffalo at 0.835 and 0.165 with heteromorphic pattern in the Nili-Ravi breed and monomorphic pattern in the Kundi breed (Table 2). NK1A to NK6B variants provides an alle- phism of the Kundi buffalo. NK2A (0.55), NK2B (0.45), NK5A (0.32), NK5C (0.68), NK6A (0.67) and NK6B (0.33) variants provides polymorphic pattern of PRKG3 gene within the Kundi breed.

The present study provides the first source of information on genetic variation in Pakistani buffaloes assessed by using PRKAG3 gene bovine chromosomes. Moderate levels of both allelic and genetic diversity were observed for the studied breeds. The SNPs in PRKAG3 gene has been linked with meat quality traits in pig and milk production traits in cattle (Kowalewska-Luczak \& Kulig, 2011; Ryan et al., 2012). As some other genes were also associated with production traits in river buffalo (Dayal et al., 2005; Pauciullo et al., 2012) therefore it is desired to confirm these polymorphisms at extensive studies in the similar or additional 
buffalo populations. These SNPs might be associated with production traits in river buffalo and the new SNPs establish in the Kundi buffalo can be used as genetic indicator of breed development programs is the practical application of the SNPs outcome. This is the first report of gene characterisation and SNPs identification in PRKGA3 gene of the Kundi as well as Nili Ravi buffaloes. Altogether, the analyses presented in this study provide preliminary data on genetic diversity and population structure of Pakistani buffalo and might be helpful for similar studies in other livestock breeds of Pakistan.

\section{ACKNOWLEDGEMENTS}

We are obliged to Higher Education Commission of Pakistan for supporting the work under Indigenous Scholarship Program batch4 (bm4260).

\section{REFERENCES}

Babar, M. E., M. Imran, M. Nawaz, B. Benkel, H. Farid, R. Jabeen, M. Abdullah, M. Javed \& M. Javed, 2008. Genetic Identification of three Pakistani buffalo breeds through a homozygosity pattern in the PRKAG3 gene. Pakistan Journal of Zoology, 40, 409-415.

Carling, D., 2004. The AMP-activated protein kinase cascade - a unifying system for energy control. Trends in Biochemistry Science, 29,18-24.

Cheung, P.C., S.P. Davies \& D.G. Hardie, 2000. Characterization of AMP-activated protein kinase $\gamma$-subunit isoforms and their role in AMP binding. Journal of Biochemistry, 346, 659-669.

Ciobanu, D., J. Bastiaansen, M. Malek, J. Helm, J. Woollard, G. Plastow \& M. Rothschild, 2001. Evidence for new alleles in the protein kinase adenosine monophosphate-activated $\gamma 3$-subunit gene associated with low glycogen content in pig skeletal muscle and improved meat quality. Genetics, 159,1151-1162.

Crute, B. E., K. Seefeld, J. Gamble, B. E. Kemp \& L. A. Witters, 1998 Functional domains of the $\alpha 1$ catalytic subunit of the AMP-activated protein kinase. Journal of Biological Chemistry, 273, 35347-35354.

Dayal, S., T. K. Bhattacharya, V. Vohra, P. Kumar \& A. Sharma, 2005. Genetic polymorphism of alpha-lactalbumin gene in riverine buffalo. DNA Sequence, 16, 173179.

FAO, 2011 Animal production and health guidelines. Molecular Genetic Characterization of Animal Genetic Resources. Commission on Genetic Resources for Food and Agriculture Food and Agriculture Organization of the United Nations. Rome, Italy.

Kowalewska-Luczak, I. \& H. Kulig, 2011. Association between polymorphism in bovine PRKAG3 gene and milk production traits. Russian Journal of Genetics, 47, 1008- 1011

Michelizzi, V. N., M. V. Dodson, Z. Pan, M. E. J. Amaral, J. J. Michal, D. J. McLean, J. E. Womack \& Z. Jiang, 2010. Water buffalo genome science comes of age. International Journal of Biological Sciences, 6 , 333-349.

Milan, D., J. T. Jeon, C. Looft, V. Amarger, A. Robic, M. Thelander, C. Rogel-Gaillard, S. Paul, N. Iannuccelli, L. Rask \& H. Ronne, 2000. A mutation in PRKAG3 associated with excess glycogen content in pig skeletal muscle. Science, 288, 12481251.

Pauciullo, A., G. Cosenza, R. Steri, A. Coletta, A. La Battaglia, D. Di Berardino, N. P. Macciotta \& L. Ramunno, 2012. A single nucleotide polymorphism in the promoter region of river buffalo stearoyl CoA desaturase gene (SCD) is associated with milk yield. Journal of Dairy Research, 79, 429-435.

Rozan, S. \& J. H. Skaletsky, 2000. Primer3 on the WWW for general users and for biologist programmers. In: Bioinformatics 
Identification of novel single nucleotide polymorphisms in the PRKAG3 gene of Pakistani river buffalo

Methods and Protocols: Methods in Molecular Biology, eds S. Krawetz \& S. Misener, Humana Press Totowa NJ, USA, pp.365-386.

Ryan, M. T., R. M. Hamill, A. M. O’Halloran, G. C. Davey, J. McBryan, A. M. Mullen, C. McGee, M. Gispert, O. I. Southwood \& T. Sweeney, 2012. SNP variation in the promoter of the PRKAG3 gene and association with meat quality traits in pig. BMC Genetics, 13, 66.

Shah, S. I. 1994 A Textbook of Animal Husbandry, $7^{\text {th }}$ edn, UK. National Book Foundation, Islamabad.

Toro, M. A., J. Fernández \& J. Caballero, 2009. Molecular characterization of breeds and its use in conservation. Livestock $S c i$ ence, 120, 174-195.

Paper received 28.12.2017; accepted for publication 02.02.2018

\section{Correspondence:}

\section{T. Hussain}

Department of Molecular Biology,

Faculty of Science and Technology,

Virtual University of Pakistan,

Lahore, Pakistan 